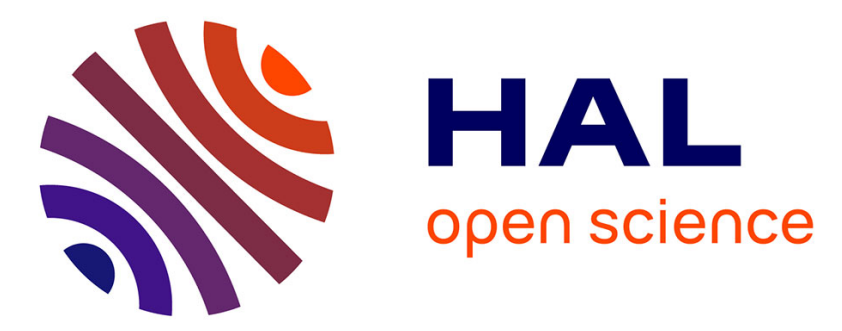

\title{
Intervention in physical education and sport: trends and developments in a decade of Francophone research
}

\author{
Mathilde Musard, Marie-Paule Poggi
}

\section{To cite this version:}

Mathilde Musard, Marie-Paule Poggi. Intervention in physical education and sport: trends and developments in a decade of Francophone research. Physical Education and Sport Pedagogy, 2013, 20 (3), pp.250 - 267. 10.1080/17408989.2013.817008 . hal-01620916

\section{HAL Id: hal-01620916 https://hal.univ-antilles.fr/hal-01620916}

Submitted on 28 Oct 2017

HAL is a multi-disciplinary open access archive for the deposit and dissemination of scientific research documents, whether they are published or not. The documents may come from teaching and research institutions in France or abroad, or from public or private research centers.
L'archive ouverte pluridisciplinaire HAL, est destinée au dépôt et à la diffusion de documents scientifiques de niveau recherche, publiés ou non, émanant des établissements d'enseignement et de recherche français ou étrangers, des laboratoires publics ou privés. 
A decade of French-speaking researches on intervention in sport (2000 - 2010)

9 University of Franche-Comté

11 Key-words : intervention, researches, literature, PE, sport

Summary for practitioners

14 This paper proposes a systematic inventory of communications presented during six ARIS

15 French-speaking congresses (Association for Research on Intervention in Sport) from

162000 to 2010 . More than 800 communications were presented, which reflect the multiple

17 facets of the intervention in physical education and in sport. A quantitative content analysis

18 of scientific programs ( $\mathrm{n}=836$ abstracts) was processed by Sphinx $\AA$ software ( 5 analysis

19 dimensions; 22 items). The treatment of the data consisted of univariate and bi-variate

20 analysis. The research field on intervention in sport is characterized in an indisputable way

21 by a beautiful expansion during this decade. The topics studied in PE, coaching and

22 training are very diversified and analysed by complementary approaches. The qualitative

23 and comprehensive researches are particularly well developed. We shall also discuss in

24 this article of the delicate relationship between the practitioners and the researchers. 
27 Abstract

28 This paper proposes a systematic inventory of communications presented during six ARIS 29 French-speaking congresses (Association for Research on Intervention in Sport) from the 30 years 2000 to 2010 . More than 800 communications were presented, which reflect the

31 multiple facets of the intervention in physical education and in sport. This legible inventory 32 of the researches on intervention can help us to identify needs and orientations for futures 33 studies and to position the French-speaking publications with regard to the English34 speaking literature. We can consider with Berthelot (2008) that the scientific activity is not 35 a social activity as the others ; it presents a certain specificity by trying to produce more and more rational knowledge. Finally, it recovers from a pragmatics (a theory of action) which wants simultaneously social, historic, contextualist but also rationalist. A quantitative content analysis of scientific programs ( $n=836$ abstracts) was processed by the Sphinx® software toward 5 analysis dimensions : (1) informations relative to the main author, (2) the nature of the communication (research, innovation report, literature review, personal

41 opinion, epistemological reflection); (3) the aim of the research (assess the efficiency of 42 the practices, transform the practices, describe andlor explain to understand the 43 practices); (4) the methodology and (5) the theme of the research. The treatment of the 44 data consisted of univariate (frequencies, percentages) and bi-variate (chi square statistic) analysis to spot possible significant relations between variables. The results show that the researches on intervention in sport: they are essentially descriptive and comprehensive, 49 using the qualitative methods. The topics studied in PE, in coaching and in training are very diversified and analyzed by complementary approaches. We see here the sign of an 51 undeniable wealth, the crossing of different theories and methods allowing a better 
52 understanding of the educational phenomena. We shall also discuss in this article of the

53 delicate relationship between the practitioners and the researchers. We observe a clear

54 and progressive increase of the researches presented during the congresses (from 55,6\% 55 in 2000 to $91,5 \%$ in 2010), whereas the other kinds of communications (literature review, 56 epistemological reflexion, innovation reports, personal opinion) seem to disappear. If the 57 distance between researchers and practitioners seems to get bigger, the trainers can play 58 a decisive role in the articulation between practice and research. 


\section{Introduction}

62 During the 90s, several congresses on intervention in physical education and in sport were organized in the francophone world. A community of practitioners, trainers, students and researchers interested in the educational practices in sport was progressively constituted: the association for research on intervention in sport (ARIS) was created in 1999. It groups

66 French in the major part, but also Canadians, Belgians, Portuguese, Tunisians, Swiss...

67 This association puts a lot into the following missions:

68 - promote and become known the researches concerning the system of the intervention in

69 the field of the physical and sports activities as well as of the human motricity (physical 70 education, training, leisure activities, adapted physical activities...);

71 - facilitate and develop the relations between all the researchers and the practitioners 72 interested in these researches in the field of the physical and sports activities, by arousing 73 exchanges and by underlining the wealth of the professional experiences;

74 - assure a help at the level of the definition of programs of research, the distribution and 75 the exploitation of their results;

76 - develop the relations with the other researchers' communities of physical and sports 77 activities, with the intention to value the researches on intervention in sport.

78 The notion of intervention gradually stands out as a key notion in the field of the sciences 79 of the motricity, the sport and the teacher training. In the $70 \mathrm{~s}$, it is the Canadian 80 researchers who chose to use the operational word of "intervention " for PE teacher 81 training. They wished to gather three roles still perceived as three different specialities: the 82 planning, the teaching and the assessment. The notion of intervention then widened in a 83 more theoretical reflection about what is the transmission of skills about physical and 84 sports activities in various fields for the benefit of varied public: " Intervention means any 85 action and individual or collective situation to one or several persons engaged in a sports 
and physical activity, and aiming at modifications of this activity. These actions are of different natures according to the contexts within which they take place, persons whom they address, intentions of the participants and the nature of the envisaged modifications. These intentions can be of education, reeducation, coaching and performance, active lifestyle and leisure, recuperation" (Durand, 1998).

Since 2000, the association for research on intervention in sport organizes biennial events: more than 800 communications were presented from 2000 to 2010 during six congresses. They reflect the multiple facets of the intervention in physical education and in sport. Throughout this decade, the researchers developed programs with diversified approaches. That's why the members of the ARIS decided to create in 2007 the observatory of the researches on intervention in sport (ORIS) to emphasize the wealth of these plural orientations. French-speaking researchers have already proposed several analyses of the published papers in physical education pedagogy (Marsenach \& Amade-Escot, 1993 ; David, Bouthier, Marsenach \& Durey, 1999 ; Bouthier, 2001 ; Amade-Escot \& AmansPassaga, 2006). This wider study focused on the the different fields of the intervention (i.e. PE, coaching, training ...) studied by the ARIS association (2000 - 2010).

It was led within this observatory, and provides a multifaceted view of the field, by leaning on quantitative data. The purpose of the ORIS observatory is to describe and interpret the evolution of the researches on intervention in sport in varied contexts and to gather the scientific produced knowledge. This tool of scientific monitoring allows to characterize the activities of research in emergence, in processing or in obsolescence, with the ambition to result in the long term on a real and fruitful interaction between practices and researches. This legible inventory of the field of the intervention can help us to identify needs and direction for futures study and to position French-speaking publications trends with regard to the English-speaking literature. 
111 We shall show that the researches on the intervention in sport are interested in varied 112 objects by leaning on a plurality of methodological frames. By comparing the data of this 113 observatory with the American studies (Kulinna \& al., 2009 ; Ward \& Ko, 2006 ; Silverman 114 \& Skonie, 1997 ; Silverman \& Manson, 2003 ; Macdonald \& al., 2002), we shall bring to 115 light certain specificities of the French-speaking researches.

116 We can thus wonder if the researches on intervention in sport can be considered as social 117 constructions (Goodson, 1988). The social dimension is certainly essential in the scientific 118 activity. Berthelot (2008) arms itself moreover with a triple point of view to specify the 119 scientific activity as social activity, by combining the contributions of the philosophy and 120 the sociology:

121 (1) The scientific activity is subjected to collective standards, that they are intellectual, 122 institutional or cultural. So, to be recognized as researcher, it is advisable to respect 123 certain rules of scientificity and justifiable models at some point;

124 (2) The scientific activity is integrated into a situation of interaction, direct or indirect, 125 which engenders rules governing the behaviors. Interactions between the participants, 126 since the informal exchanges within a laboratory until the debates during congresses, 127 influence the development of the scientific activity;

128 (3) The scientific activity is turned to others, with an intention. The researches are 129 subjected to others to be assessed, then they are published in scientific reviews and are 130 the object of debates during congresses.

131 If these three positions send back to different theoretical frameworks, we can however 132 admit that researchers, according to their intentions, weave between them, in the 133 situations where they are, interactions with specific rules, while integrating institutions and 134 organizations, which define collective norms.

135 Can we assert for all that the science is a " social construction "? If the expression of 136 "social construction " knew in the 1980s and 1990s a considerable development in 
137 domains highly varied since the publication of the founding book The social construction of

138 the reality of Berger and Luckmann in 1966, it is henceforth debated. According to Hacking 139 (2001), the notion of social construction became a vague and indistinct idea, which 140 oscillates enter commonness (" everything is construct, nothing is objective ") and 141 radicality (" nothing is false, nothing is true "). This philosopher and sciences historian 142 points out in his book The social construction of what? that this expression is not still used 143 in a relevant way, as we are interested in objects in the broad sense (the persons, the 144 practices) either in the ideas that we are made of these objects (concepts, theories). He 145 proposes then a space where can coexist and articulate reality and social construction. It 146 is thus necessary to wonder about the pertinence of the notion of social construction 147 according to the studied domain. Can we assert that the scientific activity is a social 148 construction, that means a fragile and intersubjective creation, " where everything would 149 replay all the time, when everything would reinvent in every interaction with actors and in 150 singular contexts " (Lahire, 2005)? It is not nevertheless possible to deny the weight of the 151 lived experience and incorporated representations. Indeed, if the programs of research are 152 influenced by the dialogs and debates or the conversation among scholars during 153 congresses and meetings, they depend also on the history of the considered scientific field 154 and on that of the researchers. Can we consider that the science would be in reality only a 155 social construction as the other one, a speech on the reality, reflecting faiths shared and 156 interested in a group given at some point? The scientific constructions base on more 157 reflexivity, of explicitation and of argumentatives and empirical proofs than the other 158 constructions, less demanding from the point of view of the effort of the demonstration 159 (Lahire, 2005). Also, Berthelot (2008) defends that the scientific activity is not a social 160 activity as the others ; it presents a certain specificity by trying to produce more and more 161 rational knowledge. Finally, it recovers from a pragmatics (a theory of action) which wants 162 simultaneously social, historic, contextualist but also rationalist. The researchers 
163 recompose gradually programs of researches by integrating recent scientific knowledge 164 with the aim of producing more and more rational knowledge about the intervention in 165 sport.

\section{Methodology}

168 The corpus was established from the scientific programs of six ARIS congresses:

1. Congress of Grenoble (Fr) «The intervention in the field of the physical and sports activities: competence(s) in transformation? », December 14-15-16th, $2000: 144$ abstracts ;

2. Congress of Rennes (Fr) «Sports and artistic cultures - Formalization of the professional Knowledges - Practices, Trainings, Researches», December 1214th, 2002 : 139 abstracts ;

3. Congress of Louvain - La - Neuve (Bel) «Intervene in the physical, sports and artistic activities - Practices - Researches - Trainings», January 20-21-22nd, $2005: 138$ abstracts ;

4. Congress of Besançon (Fr) « Co-construct the knowledge: the professions by the intervention in the physical, sports and artistic activities ", May 9-10-11-12th, 2006: 157 abstracts ;

5. Congress of Rodez (Fr) « The intervention in sport and its institutional contexts: cultures and peculiarity of the action », May 14 - 15 - 16th, 2008: 149 abstracts ; circles of life », May 27-30th, 2010: 106 abstracts. 
186 The content analysis (Bardin, 2001; Weill-Barais, 1997) of 836 summaries was realized 187 with the Sphinx software ${ }^{1}$. After several floating readings, 22 items in the form of closed 188 questions (essentially multiple choices) were informed through five dimensions of analysis:

189 1. General informations about the communication (congress, gender and profession 190 of the main author, institution and country);

1912 2. The nature of the communication (research, innovation report, literature review, 192 personal opinion, epistemological reflection);

193 3. The aim of the research (assess the efficiency of the practices, transform the 194 practices, describe andlor explain to understand the practices);

195 4. The methodology of the research (data collection and treatment);

196 5. The theme of the research, according to the analyzed context (PE, coaching, 197 teacher/trainer training).

198 The software offers an environment to code the texts according to the preconceived 199 variables and categories. The quantitative treatment of the data consisted of univariate 200 (frequencies, percentages) and bi-variate (chi square statistic) analysis to spot possible 201 significant relations between variables.

\section{Results}

3.1. An international community of research in expansion

If French are widely represented during congresses, we notice a more and more important 207 participation of the other nationalities, in particular the Canadians and the Belgians. All in 208 all, it is 18 nationalities and more than hundred of research laboratories which are 209 represented. International collaborations between several research laboratories (joint210 management of thesis, common research project, compared education studies...) are

\footnotetext{
${ }^{1}$ We thank Jean-François Robin and Sophie Richard (University of Paris 12) for their precious help in the data capture.
} 
211 fruitful by gathering theoretical and methodological tools. But laboratories specialized in

212 the field of intervention in sport remain little represented in the research world. We count 213 about twenty French-speaking research teams on intervention which publish regularly

214 during each congress (between 15 and 60 communications from 2000 to 2010). So, the

215 field of the research on education developed well with many international associations of 216 research, but the researchers have to continue to fight in the universities of the whole 217 world to defend this still marginalized field (Kirk, Macdonald \& O'Sullivan, 2006).

Figure 1

221 The figure 1 shows that students (essentially PhD students) represent a third of first 222 authors. This important proportion of young researchers is very promising for the 223 development of the research on intervention in sport. In fact, the young researchers seem 224 particularly active both in the French-speaking world and in the English-speaking world. 225 Macdonald and al. (2002), Kulinna and al. (2009) confirm this increasing 226 internationalization of research reviews, postgraduate students and employment 227 opportunities in universities. On the other hand, about $40 \%$ of first authors are researchers $228(22,7 \%$ of assistant professors and $16,9 \%$ of professors). Finally, it is the trainers (15\%) 229 and the practitioners (teachers : 4\%, coachs : 1\%) that are under-represented. Most of the 230 trainers develop at the same time a double activity of teaching and researching in the 231 universities (Master's degree, thesis), particularly in the european context of the training 232 by/for research. There also, this datum is encouraging because the trainers play a decisive 233 role in the relation between practice and research : they can help the practioners to 234 analyze the practices toward scientific tools and knowledge. At last, the low percentage of 235 practicionners shows how much it is difficult for the teachers and trainers to put a lot into 
236 the research. We shall discuss later in this article this low and disturbing participation of 237 the professionals of intervention.

241 Figure 2 presents the percentage of men and women publishing as first author from 2000 242 to 2010 . On average, only a third of first authors (34\%) is feminine. But it is interesting to note the encouraging increase of the percentage of women as first author : from $22,2 \%$ in

2442002 to $46 \%$ in 2010 . The comparison of these data with those of Ward and Ko (2006) in 245 the Unites States brings to light similarity. These authors study the percentages of men 246 and women publishing as first author in the American review JTPE (Journal of Teaching in 247 Physical Education) and observe also that however the distribution between men and 248 women become more and more balanced, women publish less than their male colleagues. 249 The women have entered the academy much later that the men ; these spend a higher 250 percentage of time engaged in research activities, whereas women spend more time 251 teaching and providing service activities (NCES, 2000). The inequity relative to women's 252 opportunity to publish persists in both English-speaking and French-speaking worlds of 253 research on intervention, as moreover in numerous disciplines.

\subsection{Evolution of the kinds of communications}

256 Figure 3 shows a clear and progressive increase of the percentage of researches 257 presented during the congresses (from 55,6\% in 2000 to $91,5 \%$ in 2010). The research 258 field on intervention in sport is characterized in an indisputable way by a beautiful 259 expansion during this decade. Thesis students, researchers and trainers choose to expose 260 their whole research by following the classical model (introduction / methods / results / 261 discussion) to become academically recognized as contributors to scientific knowledge. 
262 But at the same time, the other communications (literature review, epistemological 263 reflexion, innovation reports, personal points of view about teaching, training..) seem to 264 disappear. By comparison, the percentage of researches published in the American 265 Journal of Teaching in Physical Education is less important (68\% according to Ward \& Ko, 266 2006). We can wish than the different kinds of communication are presented, because 267 they reflect complementary analyses of the practices. It is not evident to favor the relations 268 between researchers and practitioners ; it's particularly difficult for practitioners who didn't 269 develop a research activity to participate to the debates during congresses. That's why the 270 trainers play a decisive role to spread the scientific knowledge in universities.

Figure 3

3.3. Contexts studied in researches on intervention in sport

Figure 4

278 Three main contexts of the intervention in sport are studied (figure 4): the PE (more half of 279 the researches), the training (24,9\%) and the coaching $(19,2 \%)$. So, the ARIS association 280 gathers numerous researchers who study the PE. This trend can be explained by the fact 281 that most of the researchers on intervention have a professional experience in PE 282 teaching. They turn thus quite naturally to studies on the PE. In certain countries, as in 283 France, the PE teachers intervene exclusively in the second degree, contrary to other 284 countries as Canada where they intervene in the first and second degrees. The 285 researches on the PE in primary school (20\% of the researches on the PE) are thus 286 particularly more developed by the Canadians. As the ARIS wants to gather researches on 
sport in various contexts of intervention, we can wish that researches on coaching, 288 physical adapted activities or leisure activities develop in the near future.

3.3.1. Research themes in PE

Figure 5

294 The data treatment shows a wide range of topics investigated, with 6 themes which represent each more than $10 \%$ of the researches. $40 \%$ of studies are centred on the teacher activity, particularly during the interactive phase of the teaching (instruction and classroom management, teaching planning and assessment) and on the teachers 298 knowledge. But the current researches are not any more focused exclusively on the 299 teaching or on the teacher, but also on the student activity $(30 \%$ with perceptions and 300 learning strategies), the physical content knowledge $(16,4 \%)$, the gender $(10,4 \%)$ and the 301 teacher-students interactions. This moving from a focus on teaching toward a focus on 302 teachers and students is also noted in the study of the American Journal of Teaching in 303 Physical Education (Ward \& Ko, 2006), but in a less marked way. Kulinna \& al. (2009) 304 observe that the dissertations on teaching in PE have focused on teacher effectiveness, 305 but there has been a recent movement to enhance the initial studies on motor skills 306 through studies of student attitude, cognition, decision making and emotion. The evolution 307 of the scientific paradigms (e.g. the process - product paradigm, the teacher thinking 308 paradigm, the mediating process paradigm and the ecological paradigm, according to 309 Cloes \& Roy, 2010) allowed to developp the themes of researches and to seize better the 310 complexity of the intervention. 
315 Contrary to the results observed in PE, it is the activity of the participants (athletes) that is

316 more studied than the activity of the educator, with two main research themes:

317 - the activity of the athletes is firstly studied (34,1\%): what are the significant structures of 318 the activity of the athletes? What do they think of their coachs? Which kind of knowledge 319 do they mobilize?

320 - the second theme " coach intervention" (26\%) is essentially centred on the choices, the 321 strategies and the adaptations of the coach during the interactive phase with the 322 sportsmen.

323 This trend can be explained by the aim of performance in the field of the coaching: the 324 scientific knowledge concerning the perceptions and the strategies of the sportsmen 325 should contribute to improve the results of these.

3.3.3. Research themes in training

331 Concerning the field of the training, the researchers analyse mainly the pre-service training of PE teachers. The in-service training remains enough little studied $(7,5 \%$ of researches on training). Nevertheless, the need for professional development of physical education

334 teachers in particular has been highlighted in a number of recent reports (O' Sullivan, 335 2008), which noted there is better value to be gained by investing in professional 336 development than in lengthening pre-service preparation.

337 As the researchers teach in universities, they need to understand how the future teachers 338 beginn and perceive their teaching activity. They thus study much more the beginner 
339 teachers activity (about 60\%) that the trainer activity (14\%). They quite particularly wish to

340 study the professional development of beginners $(36,9 \%)$, then the students activity 341 (strategies, perceptions : $21,3 \%)$ and the trainer - students interactions $(7,5 \%)$. On the

342 other hand, they try to improve the training (innovating training: $16,9 \%$ ) by experimenting 343 several kinds of interactions students-trainer or researcher-trainer.

\subsection{The aims of the researches}

346 We leaned on the works of Bru (2002) and Astolfi (1993) to distinguish three aims of the 347 researches:

348 (1) to assess the efficiency of the practices;

349 (2) to transform the practices and to innovate;

350 (3) to describe / explain to understand the practices.

351 Concerning the aim "to assess the efficiency of the practices", the researchers compare 352 different practices (e.g. constructivist practices / technicist practices) to identify the most 353 successful. They also estimate the effects of the practices on learning (e.g. impact of the 354 reflexive activity of students or of tutelage) and measure the effects of innovating programs 355 (health education) in different contexts (PE, coaching, teacher education ...).

356 When the researchers want to transform the practices, they analyze a professional 357 problem, propose an innovation and finally observe the effects of the experimentation. 358 These innovations concern the didactic treatments of various sports activities (reflexion 359 about physical content knowledge, teaching methods, settings, assessment...) and the 360 teacher education (collaborative researches between teachers and researches, interaction 361 modalities between the student and the trainer, the help to the novice teachers...).

362 At last, the researchers describe / explain the practices to better understand the activity of 363 the professionals (planning, management of the groups, instruction, communication, 364 assessment, professional development) and different publics as students or sportsmen 
365 (experiences, perceptions, strategies, linguistic interactions). These researches are 366 qualified as heuristics.

369 Figure 8 shows that $80 \%$ of the researches is in aim heuristic. These data do not evolve 370 during the decade. In front of complex, uncertain and autonomous practices, it's difficult for 371 the researchers to prescribe intervention strategies to the practitioners, because the 372 generalization of results obtained in a singular context remains very problematic. That is 373 why they turn more and more to descriptive / explanatory and comprehensive researches, 374 anchored in authentic contexts. They wish to seize the complexity of the human practices 375 and to describe very finely, by case studies, the activity of the individuals in natural 376 context. This type of research is major in the field of the intervention in sport, because the 377 activity partially shapes in relation with the specificities of the contexts. The impossibility to 378 check numerous variables in unpredictable environment explains why the other types of 379 researches are thus rarer. Indeed, it is not because a teaching method is effective in a 380 class that it will be it for all that in another class. It is the same problem for an innovation, 381 that could give variables effects according to the considered public. This important 382 proportion of researches heuristics can also be explained by the necessity of better 383 understanding at first the system of the intervention before proposing transformations. 384 Nevertheless, we can wonder so more balance between the two aims of the researches 385 "to understand the practives" and "to transform the practices" would not be desirable in the 386 longer term. If the researches heuristics can constitute relevant resources to question the 387 practices of intervention and thus eventually transform them, they remain little known by 388 the trainers and all the more the practitioners. The researches with transformative aim, by 389 taking into account the results of comprehensive researches, elaborate and estimate 390 various modalities of intervention or training in several APSA, or still invite the practitioners 
391 to collaborate throughout the process of research. Through these propositions or 392 reflections, most of the professionals can certainly conceive more easily than the 393 researches may present a social utility.

394 This orientation of the French-speaking studies towards the descriptive and 395 comprehensive researches contrasts sharply with the American researches. Indeed, 396 Silverman and Manson (2003) analyze more than 500 theses in PE from 1985 till 1999. 397 They underline the ascendancy of researches centred on the efficiency of the teacher 398 (92,5\%), among which $42,8 \%$ of researches centred on the comparison of various 399 teaching methods and $23,4 \%$ of descriptive researches, while $4 \%$ of the researches 400 concern the cognition of the teacher and 3,5\% the development of tools for the 401 intervention. To note that another study of Silverman and Skonie (1997) analysing 179 402 articles of research in PE published between 1980 and 1994 ends in similar trends.

403 The difference of studied periods cannot explain completely the important variation about 404 the aims of the researches: the French scholars produce essentially descriptive and 405 comprehensive researches while the Americans focus on the efficiency of the teaching. 406 We can put the hypothesis that the research practices are historically and culturally 407 situated. Every field of research has its own trajectory (Kirk, Macdonald and O' Sullivan, 408 2006) and develop certain paradigms and theoretical frameworks according to the political, 409 cultural, historic and social context of the country.

4113.5. A crossing of research methodologies

412 Figure 9 illustrates the methods of data collection implemented in the researches. Two 413 techniques are widely spread with a significant difference: the interview $(56,4 \%)$ and the 414 observation (54,2\%). Questionnaires, written tracks (documents, programs, articles) and 415 tests are much less used (respectively 22,6\%, 14,6\% and 7,2\%). These stabilized 
416 results, from 2000 till 2010, show that the majority of the researchers cross the 417 observations and the verbalizations to analyze the intervention in sport.

421 So, the researchers try to approach in closer the complexity of the practices. They integrated that the observation of the behaviour is not any more enough for understanding the practices. In fact, the researchers cross two different techniques, sometimes 3 or even more. $39 \%$ of the researches combine the observation with the interview (mostly the observation in authentic context with an interview of auto-confrontation or a semi-directive interview). Other forms of methods crossing are less often used: interview and analysis of documents (14,6\%) ; interview and questionnaire $(13,9 \%)$ or observation and analysis of documents $(12,2 \%)$.

This "triangulation" of data extracted from different sources represents a relevant strategy

430 of validation in qualitative research (Huberman and Miles, 1991 ; Van Der Maren, 1995 ).

431 "The triangulation consists in redrawing the most causal possible chain (...) by trying to 432 obtain more than a type of measure from more than a source for every link of the chain " 433 (Huberman and Miles, 1991, p. 427). It is supposed to confirm a result by showing that the 434 independent measures that we made it go to the same sense, or at least do not contradict 435 themselves and allows to estimate better the credibility of the results.

436 The French-speaking researches in the field of the intervention are more qualitative than 437 quantitative. Indeed, at least a quarter of the researches are dedicated to case studies and 438 another quarter is interested in small samples, lower than 30 individuals. This trend is 439 inverted in the US even if the qualitative researches tend to develop recently. The use of 440 the quantitative methods doubtless dominate the researches in PE (approximately $18 \%$ of 441 qualitative researches according to Silverman \& Manson (2003) and Ward \& Ko (2006). 
442 We can suppose that more and more researches on intervention will cross quantitative 443 and qualitative methods to benefit from the complementarity of these two types of 444 methodologies.

\section{Conclusion}

447 The purpose of this article was to present an inventory of the communications produced 448 during the first six ARIS congresses from 2000 till 2010. The results show that the 449 scientific activity in the field on the intervention in sport is in expansion and they bring to 450 light specificities of the French-speaking researches: they are essentially descriptive and 451 comprehensive, using the qualitative methods. The topics studied are very diversified and 452 the same topics can be analyzed by different and complementary approaches. We see 453 here the sign of an undeniable wealth, the crossing of different theories and methods 454 allowing a better understanding of the educational phenomena.

455 On the other hand, the professionals seem less and less present during the congresses. 456 Nevertheless, the second mission of the association ARIS consists in facilitating and in 457 developing the relations between all the researchers and the practitioners interested in the 458 researches in the field of the physical and sports activities. It thus seems today 459 inescapable to facilitate the exchanges between professionals and practitioners. But it is 460 not easy to become known these results of researches with the practitioners. These 461 difficulties can be explained by the fact that the professionals and the researchers do not 462 exercise the same job and thus do not pursue the same purposes. The professionals have 463 to resolve everyday and in the urgency various problems. A minority of them participate in 464 congresses and train in research. The research often appears as remote from the reality, 465 without utility for the practice. As for the researchers, little publish in the professional 466 reviews, not recognized in the university context. They rarely have the opportunity to 467 address specially the professionals to present and discuss their works. Nevertheless, it is 
not possible to conceive the training without taking into account the numerous and current researches on the intervention. Certainly, the results of researches cannot be considered as prescriptions or ready-made solutions because of the specificities of each context of intervention. The professional knowledge is not a linear translation of scientific knowledge which would be simplified. It results from a complex process of transformation and its appropriation passes by an interbreeding with faiths, personal conceptions and a dialectic perms with the experience (Collinet, 2006). Better to know and to understand the practices, to investigate the possible can help the professionals of the intervention to question their activity and to shape tools to analyze finely the practices.

This first inventory of the researches presented during ARIS congresses deserves to be completed by a reflection on the mobilized theoretical frames. This following project has just been realized by the members of the ORIS, who gathered in the book " sciences of the intervention in PE and in sport: results of researches and theoretical foundations" (Musard, Loquet and Carlier, 2010) 10 complementary theoretical approaches: 1) the ecological paradigm (Cloes \& Roy), 2) the psycho-sociological approaches of teaching (Dupont, Delens, Tessier \& Cogérino), 3) the cognitive anthropology (Gal, Sève, Cizeron \& Adé), 4) the clinic of activity (Lémonie \& Robin), 5) the semiotic approach (Alin \& Wallian), 6) the clinic didactic of PE (Terrisse, Carnus \& Loizon), 7) the socio-didactic approach (Poggi, Verscheure, Musard \& Lenzen), 8) the cultural anthropology (Léziart), 9) the technological approach (Mouchet, Amans-Passaga \& Gréhaigne) and 10) the didactic in PE and in physical and sport activities (Amade-Escot \& Loquet). We consider with Eid \& Diener (2006) that those multiple paradigms to investigate research questions are very promising by providing complementary perspectives and data.

\section{Références}


493 Amade-Escot, C. and Amans-Passaga, C. 2006. Quality Physical Education : A review 494 from Situated Research (1995-2005). Part One :"Curriculum and Content Issues". 495 International Journal of Physical Education, a Review Publication, 43/4, 162-172.

496 Artigue, M. 1990. Ingénierie didactique. Recherches en didactiques des mathématiques, 497 9(3), 283-307).

498 Astolfi, J.P. 1993. Trois paradigmes pour les recherches en didactique. Revue française 499 de pédagogie, 103, 5-18.

500 Bardin, L. 2001. L'analyse de contenu. Paris : PUF.

501 Berger, P. and Luckmann, T. 1986. La construction sociale de la réalité. Paris : Méridiens 502 Klincksieck.

503 Berthelot, JM. 2008. L'emprise du vrai, connaissance scientifique et modernité. Paris : 504 PUF.

505 Bouthier, D. 2001. L'intervention en EPS, panorama des axes et des types de recherches 506 conduites ces dernières années. In J. Aubert, M. Durand \& R. Refuggi (Eds.), 507 L'intervention dans le domaine des activités physiques et sportives : compétence(s) en 508 mutation ? [CD-ROM]. Grenoble : IUFM.

509 Bru, M. 2002. Pratiques enseignantes : des recherches à conforter et à développer. Revue 510 française de pédagogie, 138, 63-71.

511 Cloes, M. and Roy, M. 2010. Le cheminement de l'approche écologique : du paradigme 512 processus-produit au modèle heuristique du processus enseignement-apprentissage (13513 35). In M. Musard, M. Loquet and G. Carlier (Eds.), Sciences de l'intervention en EPS et 514 en sport. Paris : EPS.

515 Collinet, C. 2006. Une analyse sociologique des savoirs scientifiques comme ressources 516 possibles de l'action d'enseignants d'EPS et d'entraîneurs. Revue STAPS, 71, 115 - 133. 
517 David, B., Bouthier, D., Marsenach, J. and Durey, A. 1999. French research into didactics 518 and technology of physical activities and sports. An expanding new field. Instructional 519 Sciences, 15, 148-162.

520 Durand, M., Euzet JP. and Refuggi, R. 1998. L'intervention dans le domaine du sport et 521 de la motricité humaine. Disponible sur internet au format PDF à l'adresse : 522 http://www.unice.fr/ufrstaps/colloque_antibes/Durand/introantibes.htm (consulté le 5 523 Novembre 2008).

524 Eid, M., and Diener, E. 2006. Handbook of multimethod measurement in psychology. 525 Washington, DC: American Psychological Association.

526 Goodson, IF. 1988. The Making of Curriculum: Collected Essays. Lewes : Falmer.

527 Hacking, I. 1999. The social construction of what ?. Cambridge : Harvad University Press.

528 Huberman, A and Miles, B. 1991. Analyse de données qualitatives : recueil de nouvelles 529 méthodes. Bruxelles : De Boeck Université.

530 Kirk, D., Macdonald, D., and O'Sullivan, M. 2006. The Handbook of Physical Education. 531 London: Sage.

532 Kulinna, P., Scrabis-Fletcher, K., Kodish, S., Phillips, S., and Silverman, S. 2009. A 533 decade of research literature in physical education pedagogy. JTPE, 28 (2), 119-140.

534 Lahire, B. 2005. L’esprit sociologique. Paris : La découverte.

535 Macdonald, D., Kirk, D., Metzler, M., Nilges, L. M., Schempp, P., and Wright, J. 2002. It's 536 all very well, in theory: Theoretical perspectives and their applications in contemporary 537 pedagogical research. Quest, 54(2), 133-154.

538 Marsenach, J. and Amade-Escot, C. 1993. Les orientations de la recherche en didactique 539 de l'éducation physique et sportive. Revue française de pédagogie, 103, 33-42.

540 Musard, M., Loquet, M. and Carlier, G. (Eds.). 2010. Sciences de l'intervention en EPS et 541 en sport : résultats de recherche et fondements théoriques. Paris : EPS. 
542 National Center for Education Statistics. 2000. Salary, promotion and tenure status of 543 minority and women faculty in US colleges and universities. Washington, DC : US 544 Department of Education.

545 O' Sullivan, M. 2008. Creating and Sustaining Communities of Practice Among Physical 546 Education Professionals. Ejrieps, 15, 21- 31.

547 Silverman, S. and Skonie, R. 1997. Research on teaching in physical education : an 548 analysis of published research. JTPE, 16 (3), 300-311.

549 Silverman, S. and Manson, S. 2003. Research on teaching in physical education doctoral 550 dissertations : a detailed investigation of focus, method, and analysis. JTPE, 22 (3), 280551297.

552 Van Der Maren, J.M. 1995. Méthodes de recherche pour l'éducation. Paris, Bruxelles : De 553 Boeck Université.

554 Vermersch, P. (1994). L'entretien d'explicitation. Paris : ESF.

555 Ward, P. and Ko, B. 2006. Publication Trends in the Journal of Teaching in Physical 556 Education from 1981 to 2005. JTPE, 25, 266-280.

557 Weil - Barais, A. 1997. Les méthodes en psychologie. Rosny : Bréal. 558 